\title{
MASTITIS CRÓNICA GRANULOMATOSA IDIOPÁTICA: REPORTE DE UN CASO
}

\author{
Juan Takano ${ }^{1,2, a}$, Percy Prialée $3, b$
}

\begin{abstract}
RESUMEN
La mastitis cónica granulomatosa idiopática es una enfermedad rara que se presenta en mujeres, preferentemente en edad reproductiva, con características clínicas, mamográficas, ecográficas y citológicas sugestivas de cáncer mamario. Se informa un caso de patología mamaria en paciente mujer de 35 años de edad, portadora de tumoración eritematosa, sensible, localizada en mama izquierda. La lesión fue tratada como "mastitis" con antibióticos y corticoides durante dos semanas. La persistencia de tumoración y sensibilidad, así como los controles mamográficos y ecográficos sugestivos de neoplasia, decidieron la extirpación quirúrgica. El diagnóstico histopatológico fue de mastitis crónica granulomatosa idiopática.
\end{abstract}

Palabras clave: Mastitis; Enfermedades de la mama; Enfermedades raras (fuente: DeCS BIREME).

\section{IDIOPATHIC CHRONIC GRANULOMATOUS MASTITIS: A CASE REPORT}

\begin{abstract}
Idiopathic chronic granulomatous mastitis is a rare disease in women at the reproductive life with clinic, mammographic, echographic and cytological characteristics suggestive of breast cancer. We report a case of breast pathology in a 35 years old woman who had a sensitiveness and eritematous tumor localized in the left breast. With the diagnosis of "mastitis", she was treated with antibiotics and corticoids for two weeks. Because the lesion and the sensitiveness persist and the mammographic and ecographic controls were suggestive of malignancy, the tumor was surgically removing. The histopathological diagnosis was idiopatic chronic granulomatous mastitis.
\end{abstract}

Key words: Mastitis; Breast diseases; Rare diseases (source: MeSH NLM).

\section{INTRODUCCIÓN}

La mastitis crónica granulomatosa idiopática fue descrita en 1972 por Kessler y Wolloch (1) como una lobulitis granulomatosa necrotizante de evolución crónica y de etiología desconocida, con características clínicas sugestivas de mastitis infecciosa o de lesión neoplásica.

Desde el informe de Kessler y Wolloch se han publicado más de 100 casos, la mayoría de ellos en mujeres de raza no caucásica (2). El diagnóstico presuntivo, en algunos casos, fue de mastitis y, en otros, de cáncer mamario que condujo a la ablación innecesaria de la glándula mamaria ${ }^{(3)}$.

Presentamos el primer caso de mastitis crónica granulomatosa idiopática en mujer de 35 años de edad de la casuística del Policlinico Peruano-Japonés de los últimos treinta años y de la Clínica Centenario de los últimos tres años en Lima, Perú.

\section{REPORTE DE CASO}

Mujer de 35 años de edad quien refiere haber sentido dolor en mama izquierda al contacto accidental con la cabeza de su hijo. Al examinarse la zona sensible, palpa una tumoración por lo que acude a la clínica. La paciente no refiere historia familiar de cáncer de mama. Niega traumatismo previo en la mama afectada. Tuvo una gestación cinco años antes, con parto normal. Régimen catamenial: $4 / 30$. No ha hecho uso de anticonceptivos orales durante los últimos cinco años.

Al examen clínico, se detectó zona eritematosa sensible y masa palpable de $4 \times 3 \mathrm{~cm}$ en cuadrante supero-externo y zona periareolar de la mama izquierda.

Realizado los exámenes auxiliares se diagnosticó mastitis y se indicó tratamiento con clindamicina de 300 mg cada seis horas por cinco días, amikacina de $1 \mathrm{mg}$ parenteral cada 24 horas por cinco días y $50 \mathrm{mg}$ de prednisona cada 24 horas por tres días.

Facultad de Medicina, Universidad Nacional Mayor de San Marcos, Lima, Perú.

Policlínico Peruano-Japonés, Lima, Perú

Clínica Centenario Peruano-Japonés, Lima, Perú

Médico Patólogo; b Médico Gineco-Obstetra. 

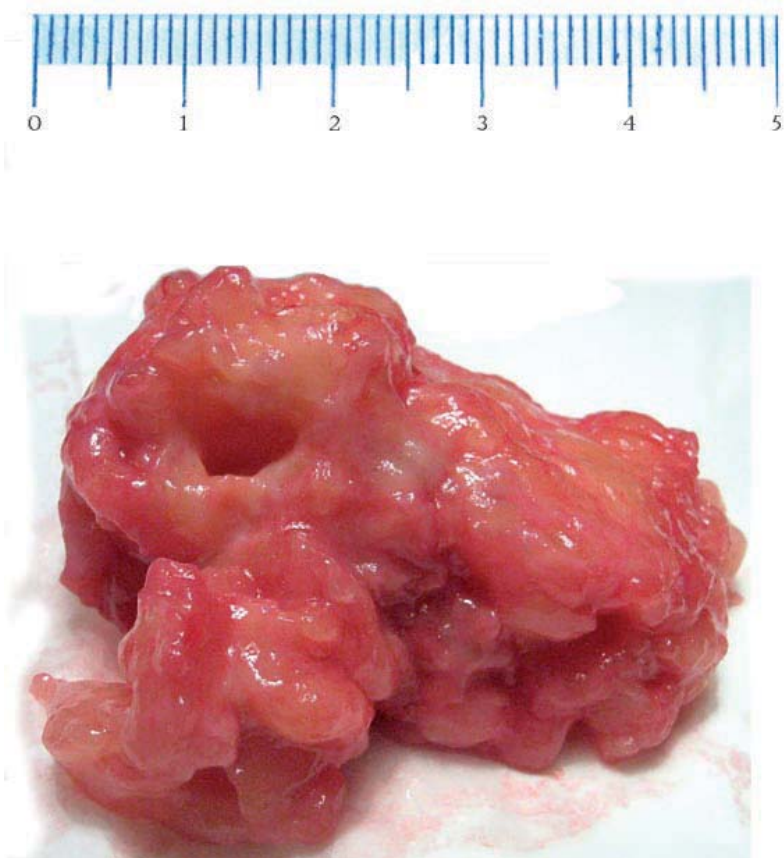

Figura 1. Imagen macroscópica de la tumoración.

Dos semanas después de haber concluido con el tratamiento, se constató la persistencia de la sensibilidad y de la tumoración. A la tercera semana la paciente recurrió a una segunda opinión médica, cuyo resultado fue presuntivo de neoplasia maligna en base a exámenes mamográficos y ecográficos de control. Con este resultado y al cumplirse la cuarta semana de evolución la paciente regresó a la clínica y se procedió a la extirpación de la tumoración.

La pieza operatoria era una masa lobulada de tejido rosado-amarillento, de consistencia firme de 4,5 x 3,4 x $3 \mathrm{~cm}$ (Figura 1). El examen microscópico de secciones representativas de la tumoración mostró denso infiltrado

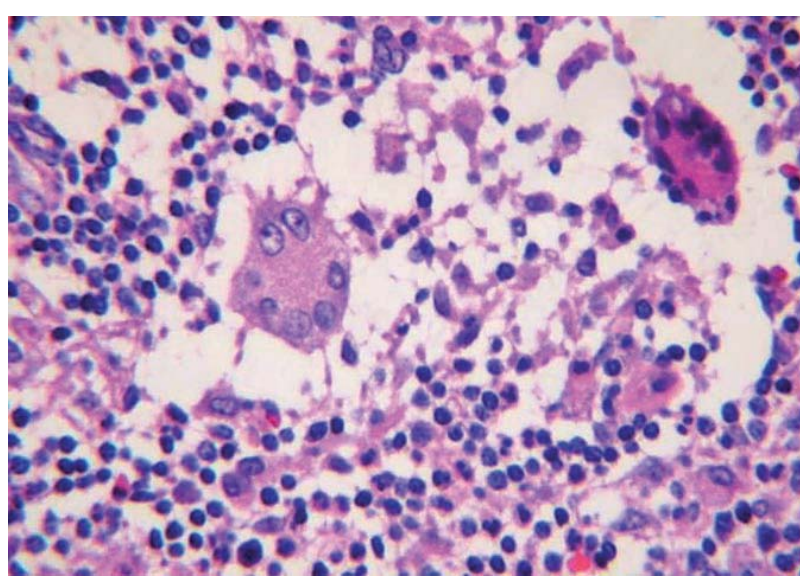

Figura 3. Granuloma con células gigantes multinucleadas tipo Langhans, linfocitos y plasmocitos. Coloración hematoxilinaeosina. X700.

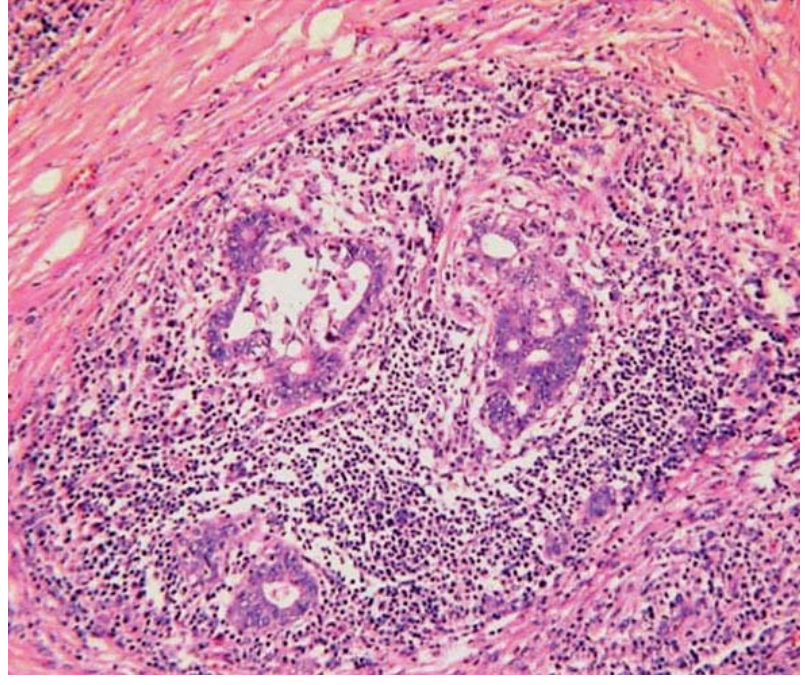

Figura 2. Infiltrado inflamatorio con linfocitos, plasmocitos e histiocitos peri e interlobular, que evidencian cambios degenerativos y regenerativos del epitelio glandular. Coloración hematoxilina-eosina. X200.

inflamatorio con linfocitos, células plasmáticas, histiocitos y células gigantes tipo Langhans y tipo cuerpo extraño a nivel inter y perilobulillar con cambios degenerativos y regenerativos del epitelio ductal (Figuras 2 y 3). En algunas áreas se observó microabscesos (Figura 4). No había necrosis caseosa y las tinciones de Ziehl-Neelsen y PAS resultaron negativas para gérmenes acido-alcohol resistentes y para hongos.

El postoperatorio cursó con hematoma en el lecho quirúrgico, que se resolvió con tratamiento pocos días después. Al mes, la paciente regresó por presentar secreción serohemática a través de orifico fistuloso que curó tres semanas después de recibir tratamiento con dexorribonucleasa, cloranfenicol y plasmina.

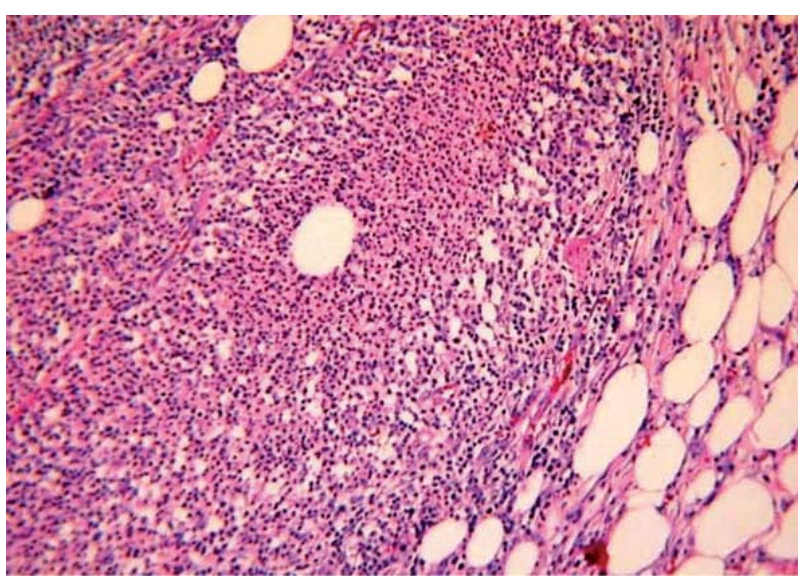

Figura 4. Microabsceso. Coloración: hematoxilina-eosina. X100. 


\section{DISCUSIÓN}

La mastitis crónica granulomatosa idiopática ha sido descrita en mujeres cuyas edades fluctúan entre 11 y 83 años, la mayoría de raza no caucásica y en edad reproductiva (2). En un estudio epidemiológico reciente, realizado en los Estados Unidos de Norte América, se ha demostrado una alta incidencia de la enfermedad en mujeres hispanas ${ }^{(3)}$. Como antecedentes se refiere el uso de anticonceptivos orales hasta en un $33 \%$ de casos, situación discutida en la patogénesis de esta dolencia. La lesión se presenta después de algunos meses hasta ocho años después de la última gestación ${ }^{(4)}$. Suele ser unilateral, aunque se ha descrito presentación bilateral hasta en $25 \%$ de casos ${ }^{(5)}$ La lesión se inicia como un proceso flogósico, doloroso al tacto, con tumoración palpable, indistintamente en cualquier cuadrante de la mama ${ }^{(5)}$; suele ulcerarse, fistulizarse y abscedarse con evolución a la cronicidad (2).

Los exámenes de laboratorio no son contribuyentes al diagnóstico y los exámenes mamográficos, ecográficos y citológicos sugieren naturaleza neoplásica de la lesión conduciendo en algunos casos a la ablación innecesaria de la glándula mamaria ${ }^{(5)}$.

El diagnóstico de mastitis crónica granulomatosa idiopática se hace histológicamente en base a granulomas que afectan primariamente las estructuras lobulares de la glándula, los que se caracterizan por la presencia de linfocitos, células plasmáticas, células epitelioides y células gigantes multinucleadas tipo Langhns y tipo cuerpo extraño, acompañados, en ocasiones, por microabscesos. Los exámenes citológicos, deben ser repetidos y confirmados por biopsia ${ }^{(6)}$. El diagnóstico diferencial debe hacerse con otras enfermedades inflamatorias granulomatosas como tuberculosis, micosis, sarcoidosis y granulomatosis de Wegener ${ }^{(5,6)}$.

La etiología de la mastitis granulomatosa idiopática, es desconocida. Se ha sugerido mecanismos autoinmunes en la génesis de la lesión ${ }^{(2)}$. Desde que muchos pacientes inician la enfermedad en el período de lactancia, se piensa que la reacción inflamatoria es una respuesta inmune local a la extravasación láctea a nivel acinar ${ }^{(5)}$. También se ha sugerido que la respuesta podría relacionarse con la lesión epitelial ducto-acinar postraumática o a infección viral que conlleva a respuesta inmune local con migración de linfocitos y macrófagos hacia la zona afectada. Hay informes de casos relacionados con deficiencia de alfa-1antitripsina y con hiperprolactinemia ${ }^{(2)}$.
No existen protocolos establecidos para el tratamiento de la mastitis crónica granulomatosa idiopática. Suele utilizarse antibióticos y corticoides ${ }^{(5)}$. En casos de persistencia o recidiva se procede a la extirpación quirúrgica. Se ha utilizado inmunosupresores como metotrexate en casos de recurrencia ${ }^{(7)}$ y se ha informado de cura espontánea en algunos casos.

\section{Financiamiento}

Policlínico Peruano-Japonés y Clínica Centenario de Lima, Perú.

\section{Conflictos de Interés}

Los autores declaran no tener conflictos de interés en la publicación de este artículo.

\section{REFERENCIAS BIBLIGRÁFICAS}

1. Kessler E, Wolloch Y. Granulomatous mastitis: a lesion clinically simulating carcinoma. Am J Clin Pathol. 1972; 58(6):642-46

2. Tuli R, O'Hara BJ, Hines J, Rosenberg AL. Idiopathic granulomatous mastitis masquerading as carcinoma of the breast: A case report and review of the literature. Int Semin Surg Oncol. 2007;4:21.

3. Centers for Disease Control and Prevention (CDC). Idiophatic granulomatous mastitis in hispanic women - Indiana, 2006-2008. MMWR Morb Mortal Wkly Rep. 2009;58(47):1317-21.

4. Bani-Hani KE, Yaghan RJ, Matalka II, Shatnawi NJ. Idiopathic granulomatous mastitis: time to avoid unnecessary mastectomies. Breast J. 2004;10(4):318-22.

5. Imoto, S, Kitaya T, Kodama T, Hasebe T, Mukai K. Idiopathic granulomatous mastitis: Case report and review of the literature. Jnp J Clin Oncol. 1997;27(4):274-77.

6. Su FH, Liu SC, Suen JH, Chen DS, Lou SMA. Idiopathic granulomatous mastitis: a case successfully treated with a minimum dose of a steroid. Chang Gung Med J. 2005;28(6):431-35.

7. Schmajuk G, Genovese MC. First report of idiophatic granulomatous mastitis, treated with methotrexate monotherapy. J Rheumatol. 2009;36(7):1559-60.

Correspondencia: Juan Takano Morón

Dirección: Av. Gregorio Escobedo 783, Jesús María, Lima, Perú.

Teléfono: (51) 998-444-377

Correo electrónico:takanojuan@yahoo.com 